\title{
Rearing and measurements of Oestrus ovis larvae and pupae (Diptera: Oestridae) from slaughtered sheep heads in Mosul abattoir -Iraq
}

\author{
N.H. Al-ubeidi ${ }^{1}$, E.R. Al- kennany ${ }^{2}$ and A.B.J. Alani ${ }^{1}$ \\ ${ }^{1}$ Department of Microbiology, ${ }^{2}$ Department of Pathology and Poultry Diseases, College of Veterinary Medicine, \\ University of Mosul, Mosul, Iraq
}

(Received September 16, 2017; Accepted November 3, 2017)

\begin{abstract}
Oestrus ovis larvae 142 were collected from the 133 heads of sheep slaughtered at the Mosul abattoir in Nineveh governorate during March-May 2014. In This study, the weight and dimensions Oestrus ovis larvae and pupae were measured and there was a significant difference between larvae of Oestrus ovis. Forty five of the third larval stage were rearing and them pupated until emergence of the adult stage. Sixteen larvae were emerged to adult (35.6\%). (4.4\%) larvae did not pupariation and $60 \%$ were not reached to adult. The puparation period taking (24-30 hours) and the pupal stage taking (23-28) days the average longevity of adult flies was 10 days. This study is regarded as the first one showing that all flies were similar in their external shape and so all were belonging to Oestrus ovis causing myiasis in sheep.
\end{abstract}

Keywords: Oestrus ovis, larvae, Sheep.

Available online at http://www.vetmedmosul.org/ijvs

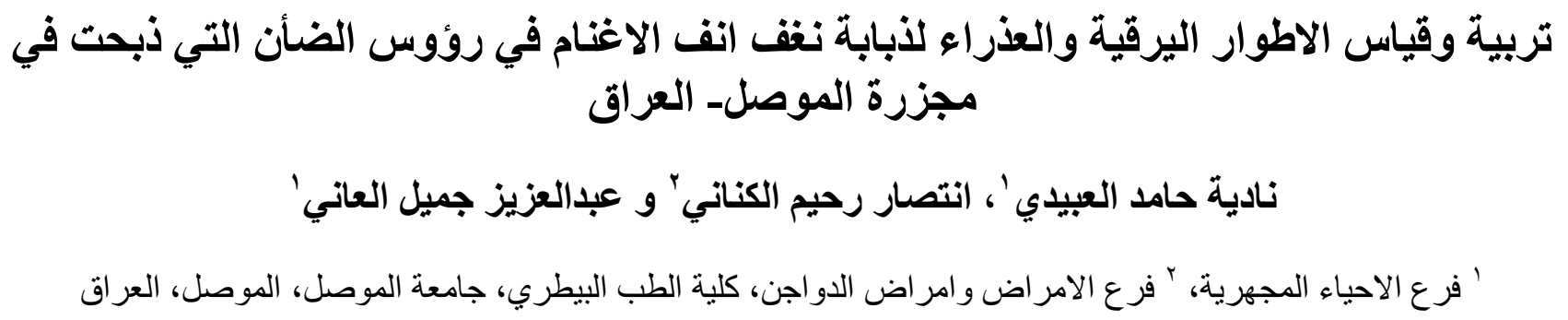

الخلاصة

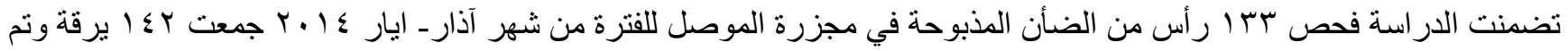

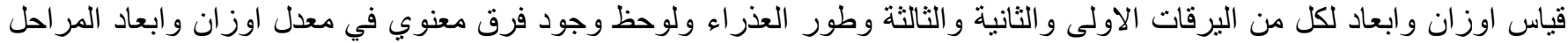

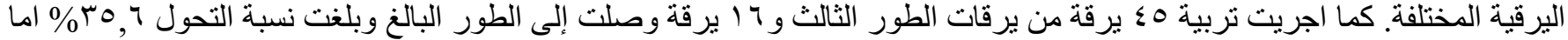

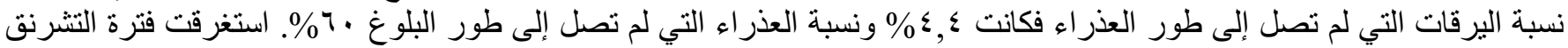

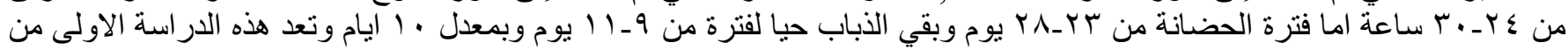

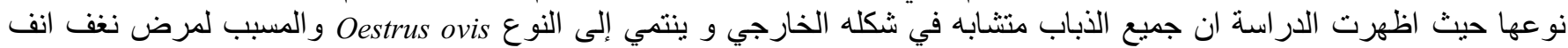

\section{Introduction}

The sheep nasal bot fly is a cosmopolitan parasite whose larvae develop in the head sinuses and nasal passages of sheep. On warm and sunny day the fly deposit the first stage larvae on the nostrils of the sheep (1).
Larvae spend a feeding period from five weeks to several months, molting twice until they become third instars (2). Mature L3 leave lost about $77 \%$ of water and $65 \%$ of fat reserves acquired during the larval stage (3). There are relationships between larval weight with pupal survival and adult size. Data analyais from laboratory and 
field-reared specimens showed that survival during intrapuparial and adult periods may be compromised when larval growth is affected, therefore larval weight acquires special relevance particularly for females because the adult gravid females must find the host and carryout larviposition to complete their life-cycles (4).

The flies are not active in the hot last months of summer and during the cold winter. This can be explained by the variation in season's months in each country and the influence of the temperature on fly's activity. Temperature is the main environmental factor regulating the life cycle of this organism during both the parasitic and free phases (5). They obtained Oestrus ovis adult within a temperature ranged from $16-32^{\circ} \mathrm{C}$, but at constant temperature of $16^{\circ} \mathrm{C}$ pupae developed while adults did not hatch also at temperature over $32^{\circ} \mathrm{C}$, since this temperature was proved to be fatal for pupae development found no influence of relative humidity on the number of adults emerging from pupae (6).

O. ovis can flourishes in different environments and has adapted to the climate predominant wherever sheep are kept, and this ability to adapt to different environments allows for the natural continuance of infestation and makes the parasite difficult to be controlled (7).

The objectives of this work were to identify the flies that emerge from the larvae collected from the heads, dimensions and weight of Oestrus ovis larvae, estimation the relationships between dimensions and weights of larvae with dimensions and weights of puparium and the newly eclosed adult; percentages of hatched adults incubation period and transformation from pupa to adult fly.

\section{Materials and methods}

The larvae of Oestrus ovis were collected from the 133 dissected heads of slaughtered sheep during the period from March and May 2014.

A total of 142 larvae were collected and identified using zumpt key with the aid of dissecting microscope, 35 of those larvae were identified as L1, 62 were identified as L2 and 45 were identified as L3. Larval weight and dimension measures were obtained according to (8).

The third stage larvae of the parasite were collected and then transferred to plastic vials containing sand and marked individually the pots were covered with gauze, and were reared under room temperature at average $23^{\circ} \mathrm{C}$ and humidity at average 44.3 .

The larvae were checked every day to assess pupal formation and the duration of this process was taken. If the time of transformation is less or equals to 10 days, it said to be P10 weight, and if more than 10 days it said to be P20 weight.

The length of pupa was measured by the distance between the prothoracic fringe and the anal tubercle, while the width by the distance between right and left lateral sides of the segment number eight (9). The adults after hatching were kept and individually marked to record their longevity. The data were analyzed statistically by One Way Anova test (10).

\section{Results}

From 133 dissected heads of slaughtered sheep a total of 142 larvae were collected. Thirty five of these larvae were in their first stage (L1), 62 were in their stage (L2) and 45in their third stage. From the 45 larvae reared a total of 16 adults flies (35.6\%), while 2 larvae $(4.4 \%)$ did not transferred $27(60 \%)$ could not transfer from pupae to adults. The emergence percentage and pupae development shown in table (1) and figure (1 and 2). The descriptive measures of the different stage of Oestrus ovis (L1, L2, L3) and puparium with general view are shown in table (2) and figure (3 and 4).

Table 1: Emergence percentages and pupal development stage of 45 third larvae of Oestrus ovis reared in room temperature

\begin{tabular}{lcc}
\hline Pupation development & No. & Prevalence \% \\
\hline Emerged to adult & 16 & 35.6 \\
No, pupae produced & 2 & 4.4 \\
Not reached to adult & 27 & 60 \\
\hline
\end{tabular}

Table 2: Descriptive statistics of the measurements of Oestrus ovis larvae and pupae

\begin{tabular}{lccc}
\hline $\begin{array}{l}\text { Dimensions/ } \\
\text { weight of individual }\end{array}$ & mean & SD & Range \\
\hline length (mm) & & & \\
\hline first stage larvae & $2.20^{\mathrm{a}}$ & 0.90 & $1-4$ \\
second stage larvae & $11.40^{\mathrm{b}}$ & 3.76 & $6-17$ \\
Third stage larvae & $23.1^{\mathrm{c}}$ & 2.8 & $18-28$ \\
Pupae (10 days) & $14.7^{\mathrm{d}}$ & 1.9 & $12-18$ \\
Pupae (20 days) & $12.4^{\mathrm{b}}$ & 1.1 & $11-14$ \\
\hline Width (mm) & & & \\
\hline first stage larvae & $0.9^{\mathrm{a}}$ & 0.3 & $0.5-1.5$ \\
second stage larvae & $3.4^{\mathrm{b}}$ & 0.8 & $2.5-5$ \\
Third stage larvae & $7.1^{\mathrm{c}}$ & 1 & $6-9$ \\
Pupae (10 days) & $6.8^{\mathrm{c}}$ & 0.7 & $6-7.5$ \\
Pupae (20 days) & $5^{\mathrm{d}}$ & 0.9 & $4-6$ \\
\hline Weight (mg) & & & \\
\hline first stage larvae & $1.40^{\mathrm{a}}$ & 0.51 & $1-2$ \\
second stage larvae & $54^{\mathrm{b}}$ & 18.1 & $20-80$ \\
Third stage larvae & $438.7^{\mathrm{c}}$ & 119.2 & $280-550$ \\
Pupae (10 days) & $408.7^{\mathrm{d}}$ & 66.1 & $270-480$ \\
Pupae (20 days) & $277.4^{\mathrm{e}}$ & 52.6 & $201-380$ \\
\hline Meas wit diffent
\end{tabular}

Means with different letters in the same column are significantly different at $\mathrm{P}<0.05$. 
The pupariation process takes about 24-30 hours during this period the individual shrank longitudinally from 23.1 to $14.7 \mathrm{~mm}$ which represents $63.6 \%$ of larval length. Eventually acquiring the typical puparial shape, differences in puparium length between p10 and p20 days were measured as shown in figure (5). The incubation and moulting periods were different taking from 23-28 days. The longevity of adult flies was (9-11 days). The emerged flies were similar in colour and morphological features when examined under the dissection microscope. These morphological features specially wing venation and black pits in the abdomen and the mouth parts are reduces to small knobs revealed that all emerged flies were Oestrus ovis species. Figure (6).

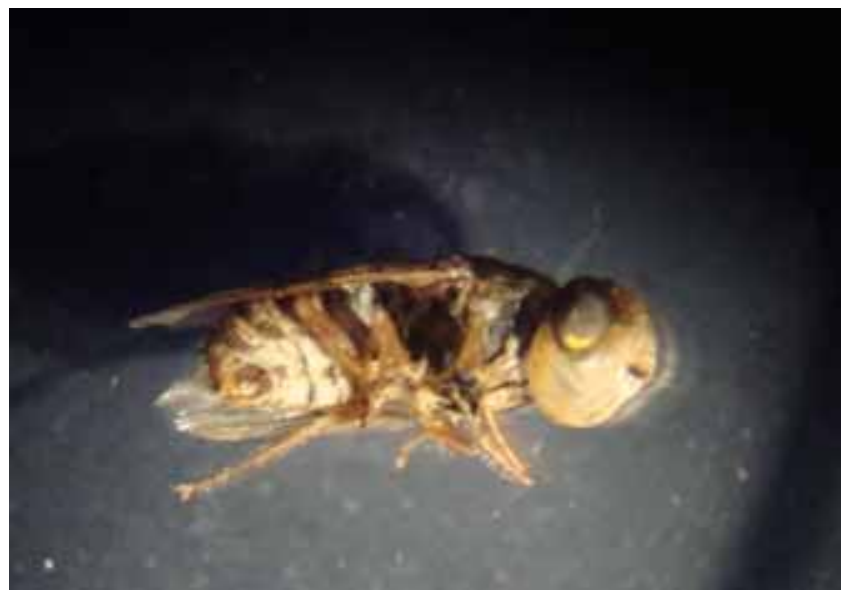

Figure 1: An adult fly of Oestrus ovis under dissecting microscope.

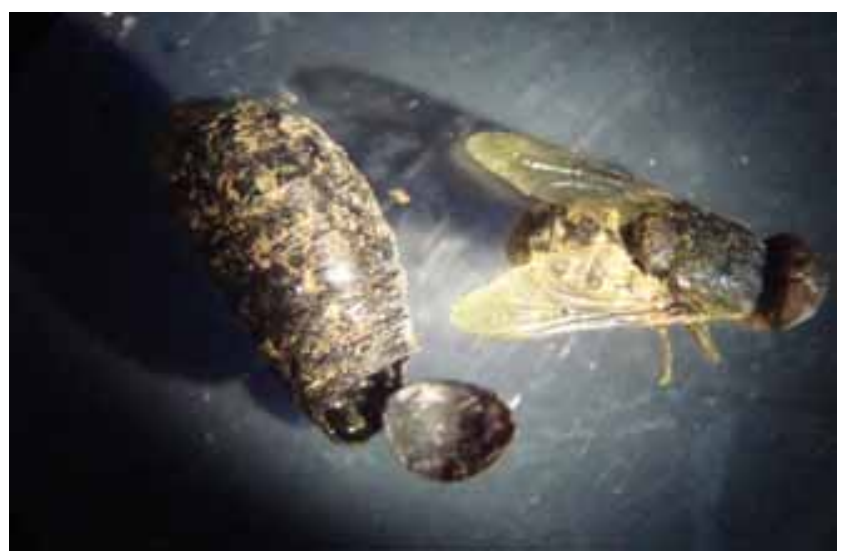

Figure 2: An adult fly of Oestrus ovis and pupae under dissecting microscope.

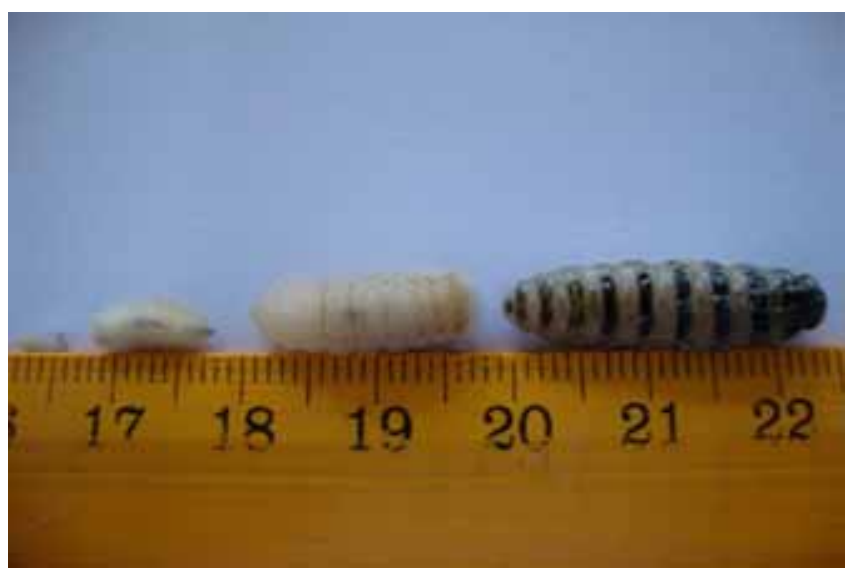

Figure 3: Dimensions(mm) of Oestrus ovis larvae.

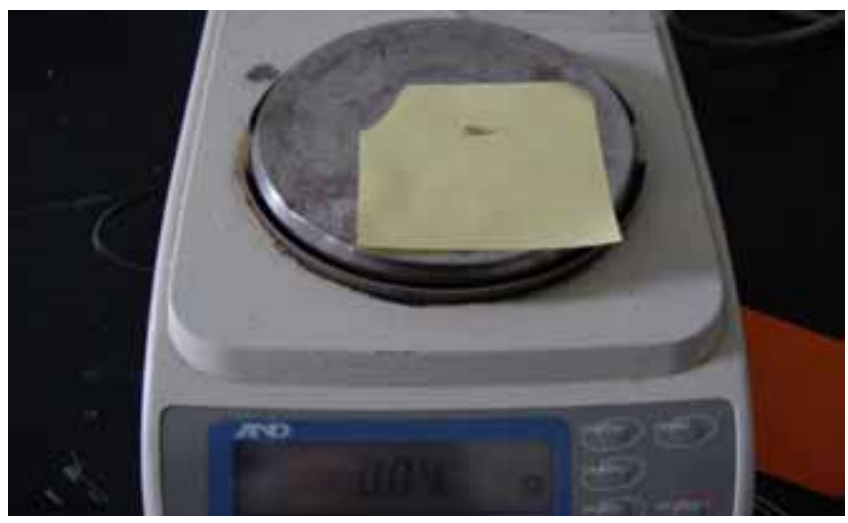

Figure 4: Weight of second stage larvae.

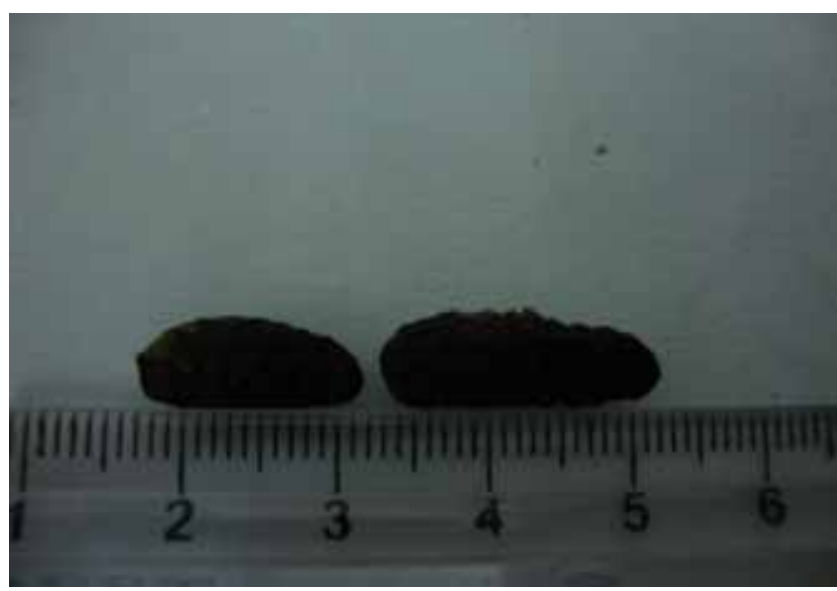

Figure 5: Length of the live puparium recorded during the 10 days and 20 days of the puparial period. 


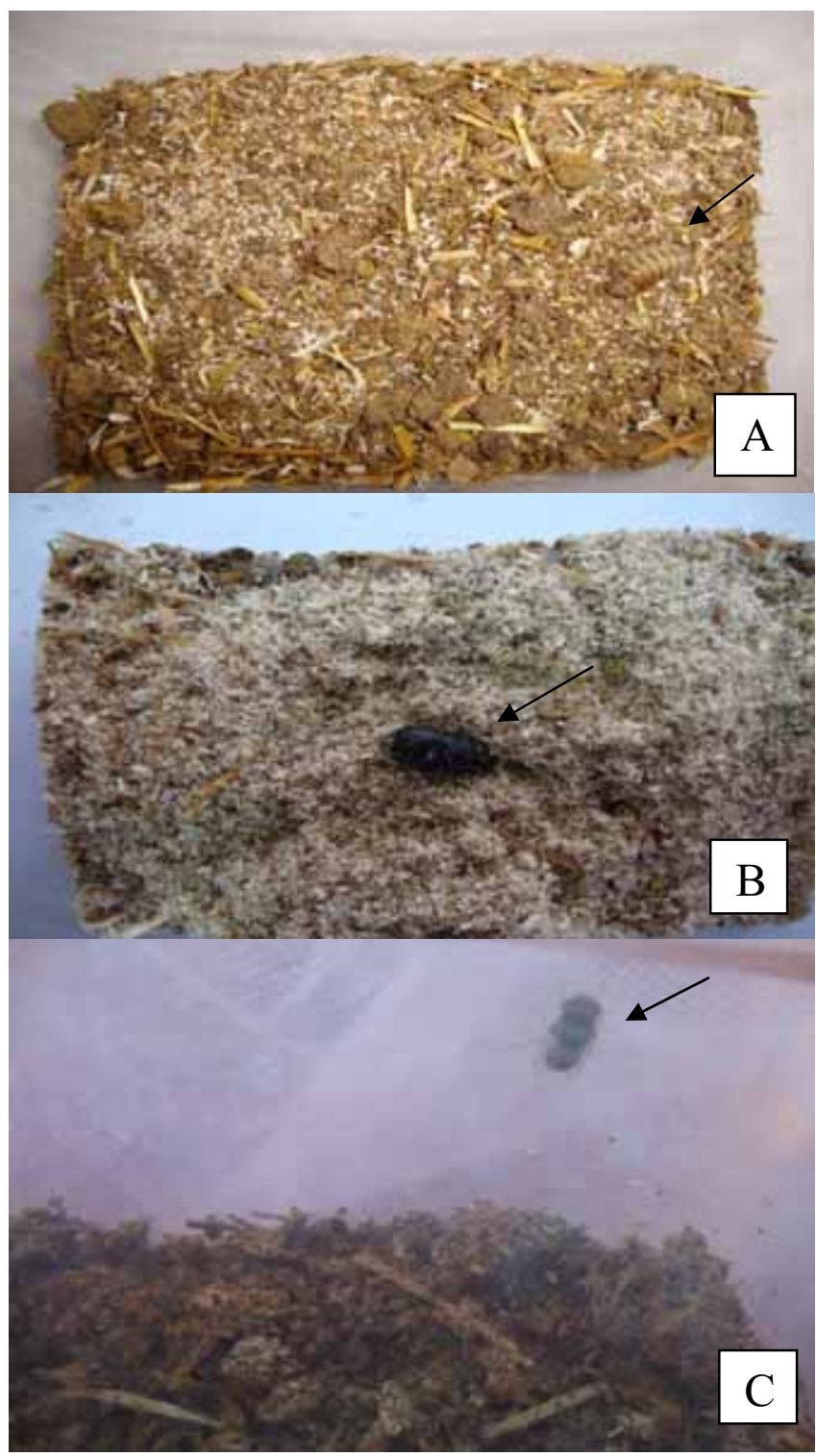

Figure 6: Developmental stage of Oestrus ovis larvae reared in room temperature. A: Mature third stage larvae in soil. B: pupa in the soil. C: An adult fly emerged from an incubated larva/pupa.

\section{Discussion}

The percentage of adult flies that amerged were similar to those recorded by (6) how obtained a hatch rate of $35 \%$ Oestrus ovis adults. but lower than these reported by (11) who found a percentage of $57.4 \%$ when larvae were incubated at $28^{\circ} \mathrm{C}$ and these rate increased up to $65.6 \%$ when larvae were reared at $38^{\circ} \mathrm{C}$ such differences may be attributed to seasonal variable in which temperature is considered the most important environmental signal regulating the percentage of adults emerging from pupa (12). In the present study all emerged flies were Oestrus ovis judging from their morphological Features. These observations showed that these flies were responsible for causing myiasis in sheep. The emerged flies in our study were grey green in colour agreeing with the finding of (13) but not with (14) who found yellow brown in colour under the dissecting microscope.

The success of pupation and adult emergence were influenced by weight and dimensions of larvae. The measurement of larvae and pupa which observed in this study are in agreement with those described by $(2,9,15-17)$.

There was significant different measurement between size and weight of larvae, pupa at 10 days and 20 day the cause of these differences might be due to the integumental skrinkage and wrinkle formation that occurs during the puparation process $(9,17)$.

In our study the length of the Pupariation period may varied from 30 hours in slightly pigmented larvae and 24 hours in heavily pigmented larvae these periods were longer than that obtained by (9). Who noted that pupariation process takes about $12 \mathrm{~h}$. the pupal period of sheep nasal bot fly can range from 23-28 days for flies that hatch normally. This incubation period is shorter than that reported by (18) in South Africa which was 60 days. Such differences may be related to different factors such seasonal differences, environmental temperature that regulates intrapuparial development (19). The longevity of the adult flies was in agreement with (20) All of these parameters will be very useful in improving our knowledge of the epizootiology of this kind of myiasis.

\section{Reference}

1. Bakhraibah AO. Prevalence and organ distribution of larval Oestrus ovis (Diptera: oestridae) Cysticercus tenuicollis and Echinococcus granulosus (cestoda: taenidae) in slaughtered sheep and goats at Jeddah in Saudi Arabia. Indian J Appl Res. 2016;6(3):501-504.

2. Capelle KJ. The occurrence of Oestrus ovis L. (Diptera: oesridae) in the big horn sheep from Wyoming and Montana. J parasitol. 1966;52(3):618-621.

3. Cepda- placios R,Angulovaladez JP,Scholl R. ecobiology of the sheep nose bot fly (oestrus ovis L): are view. Revue Med Vet. 2011;162(11):503-507.

4. Cepeda- palacios R, scholl P J. Intra-puparial development in Oestrus ovis (Diptra: oestridae). J Med Entomol. 2000;37:239-245.

5. Scale A, paz-silva A. Chronobiology of Oestrus ovis (Dipetra: oestridae) in Sardinia italy: guidelines to chemoprophylaxis. J Med Entomol. 2002;39:652-657.

6. Breev KA, zagretdinov RG, minar J. Influence of constant and variable temperature on pupal development of the sheep bot fly (oestrus ovis L) folia. Parasitol. 1980;27:359-365.

7. Da silva Bf, Machado GP. Prevalence of Oestrus ovis (Diptera: oestridae) in sheep from the sao Paulo central region, Brazil. Rev. Bras. Parasitol Vet Jaboticabol. 2013;22(1):18-21.

8. Cepe da- palacios R A,vila A, Ramirez-orduna R, Dorchies P. Estimation of the growth patterns of oestrus ovis L. larvae hosted by goats in Baja California sur, mexico. Vet Parasitol. 1999;86:119-126. 
9. Cepda- palacois R, Ruiz-ocho A C, Ramirez -orduna R. angulovaladez CE. The puparium structure of the sheep nasal botfly (oestrus ovis L.). Revue Med Vet. 2015;166(7-8):215-220.

10. Petrie A, Watson P. Statistics for veterinary and animal science black well science co. London England. 2003.

11. Omer WA. Detection of nasal bot fly larvae in slaughtered sheep head in alsalam abattoir in Khartoum state-sudan. University of Khartoum A. Ph.D Thesis. 2010.

12. Tabouret G, Jacquiet P, Scholl P, Dorchies P. Oestrus ovis in sheep relative third- instar populations risks of infection and parasitic control. Vet Res. 2001;32:525-531.

13. Papadopoulos E,dvorak L. Oestrus ovis (Linnaeus 1761) (Diptera, oestridae), first record of an adult from Greece. Parnassiana Arch. 2015;3:3-6.

14. Zumpt F. Myiasis in man and animals in the old world. Butte worth, London. 1965.

15. Angulo- valadez CE, Scala A, Grisez C, Prevot F, Bergeand JP. Specific IgG antibody responses in oestrus ovis L. (Diptera: oestridae) infected sheep. Associations with intensity of infection and larval development. Vet Parasitol. 2008;257-263

16. Moya VM, Rodriguez diego JG, Alfonso P, Martin perez J, Olivares J. Morphmetriic characterization of oestrus ovis (Dipetra: oestridae larvae from infested sheep incuba. Revsalud Anim. 2012;34(3):184187.

17. Perez JM, Granados JE, Moreno V. Intro rearing Oestrus caucasicus third- instar larvae and pupae (Dipetra: oestridae) from naturallyinfested Iberian ibex, Capra pyrenaica (Artiodactyla: bovidae). Parasitie. 2006;13:305-310.

18. Horak IG. Oestrus ovis in sheep parasites of domestic and wild animals in South Africa, ouder stepoort. J Vet Res. 1977;44(2):55-64.

19. Nilssen AC. Effect of temperature on pupal development and eclosion dates in the reindeer oestrids. Hypoderma tarandi and Cephenemyia trompe (Dipetra: oestridae). Environ entomol. 1997;26(2):296-306

20. Biggs $\mathrm{HG}$, mcclain $\mathrm{E}$, muller $\mathrm{GL}$, anthonissen $\mathrm{M}$, hare $\mathrm{KM}$. Apprediction model for strike in the sheep nasal fly, Oestrus ovis in Namibia. Preventive Vet Med. 1998;33:267-282. 